\title{
Identidade nacional e patrimônio cultural intangível: uma análise do samba, fado e tango
}

\author{
National identity and intangible cultural heritage: \\ an analysis of samba, fado and tango
}

\author{
Felipe Yera Barchi ${ }^{A}$ \\ Fabiana Lopes Da Cunha \\ ${ }^{a}$ Professor rede municipal de Paraguaçu Paulista, doutor em História pela Unesp \\ E-mail: felipeyerabarchi@gmail.com \\ ${ }^{\text {b }}$ Professora Adjunta da UNESP, Campus Experimental de Ourinhos, doutora em História pela USP \\ E-mail: fabiana.cunha@unesp.br
}

\begin{abstract}
Através de análise comparada investigamos aqui os processos de nascimento do fado em Lisboa, do tango em Buenos e do samba no Rio de Janeiro e a transformação desses estilos em símbolos nacionais de seus países. Os três gêneros surgiram no século 19, na periferia de capitais portuárias, e passaram a ter alcance nacional na era do rádio. Tal processo de se deu em meio à tutela de governos autoritários em busca de legitimação e disciplinarização popular (Salazar em Portugal, Péron na Argentina e Vargas no Brasil). Pela censura explícita de letras e comportamentos desagradáveis aos regimes, pelo patrocínio de artistas convenientes ou pelo cadastramento e habilitação de artistas "autorizados", esses estilos foram, por um lado, catapultados ao estrelato nacional e, de outro lado, viram sua liberdade artística ficar restrita. Posteriormente, analisamos a transformação desses estilos consagrados pelo público em patrimônio cultural imaterial e ativos turísticos das cidades em questão. Defendemos que esse último fator é ponto chave para se entender as iniciativas de patrimonialização nos três casos.
\end{abstract}

Palavras-chave: patrimônio cultural, turismo cultural, fado, tango, samba.

By comparative analysis, we investigate the processes of birth of fado in Lisbon, tango in Buenos Aires and samba in Rio de Janeiro and the transformation of these styles into national symbols of their countries. The three genres appeared in the 19th century in the periphery of port capitals and began to have national reach in the radio era. This process took place amidst the tutelage of authoritarian governments seeking legitimization and popular discipline (Salazar in Portugal, Péron in Argentina and Vargas in Brazil). By explicit censorship of lyrics and unpleasant behavior to the regimes, by the sponsorship of convenient artists, or by the registration and qualification of "authorized" artists, these styles were, on the one hand, catapulted to national stardom and, on the other, had their artistic freedom restricted. Later on, we analyzed the transformation of these styles consecrated by the public into intangible cultural heritage and tourist assets of the cities in question. We defend that this last factor is a key point to understand the patrimonialization initiatives in the three cases.

Keywords: cultural heritage, national identity, cultural tourism, fado, tango, samba. 


\section{INTRODUÇÃO}

Atualmente, gêneros musicais como o fado, tango e samba soam de forma similar na aldeia global: música popular e símbolo identitário de Portugal, Argentina e Brasil, respectivamente. No fim do século XX e início do XXI, além dessas duas características, esses gêneros se tornaram importantes atrativos da indústria turística, sobretudo para três cidades: Lisboa, Buenos Aires e Rio de Janeiro.

As trajetórias desses estilos musicais guardam semelhanças notórias: nasceram em setores marginais de capitais portuárias ao fim do século XIX, se "dignificaram" e dominaram as rádios no momento-chave de expansão (décadas de 1930 a 1960) e ao fim do século XX passam por processos internos de patrimonialização (mais tarde também chanceladas pela Unesco) que atendem também, mas não exclusivamente, interesses comerciais da indústria do turismo.

Ainda, não podemos nos esquecer que os movimentos que lançam esses gêneros marginais ao protagonismo dentro de cada país estão intrinsecamente relacionados a governos autoritários que usaram o rádio como estratégia principal de comunicação com as massas. Essa observação não visa negar o apelo popular genuíno e espontâneo que cerca o tango, o fado ou o samba, o objetivo é jogar luz a um período decisivo em que surgem ídolos artísticos, e esses gêneros, até então concentrados em redutos específicos, ganham amplitude nacional ${ }^{1}$.

Em que pese as diferenças notórias e significativas entre governos como o de Peron, Vargas ou Salazar, há paralelismos vitais no modo como manifestações legítimas da cultura popular são cooptadas ou instrumentalizadas por governos autoritários numa estratégia de comunicação com as massas. Porém, é necessário destacar tanto ações de resistência, quanto de negociação e adesão entre artistas e políticos, bem como considerar o impacto tecnológico tanto do rádio, quanto das técnicas de gravação nas práticas cotidianas desses gêneros populares.

Ao final, também analisamos como as iniciativas de patrimonialização estão ligadas por um lado ao contexto de redemocratização nos três países e valorização da cultura popular e, de outro, a emergência da indústria do turismo receptivo como atividades econômicas protagonistas.

1 O samba tem a particularidade de um surgimento mais difuso, tanto no tempo, quanto no espaço, porém, neste trabalho lidamos com a vertente carioca do samba, que foi a que passou por processos similares ao fado e tango.

\section{OBjetivos}

Nosso intuito principal é traçar um quadro comparativo internacional para melhor entendermos as dinâmicas que envolvem a produção de narrativas identitárias, políticas e patrimoniais envolvendo gêneros musicais de grande apelo popular. Se as trajetórias iniciais podem ser vistas como fenômenos coincidentes no que diz respeito à questão patrimonial - e turística -, podemos notar conexões. Como aponta Eduardo Falcão:

A classificação do fado a Património Cultural Imaterial não é um caso isolado de género musical patrimonializado. Antecedem a classificação do fado como Património Cultural Imaterial, o samba-de-roda no Brasil, em 2004, o canto a tenore na Itália, em 2008, o tango na Argentina-Uruguai, em 2009, e o flamenco na Espanha, em 2010. (FALCÃO, 2017, p. 13)

Por mais que apelem à "alma nacional" e à originalidade, esses estilos guardam semelhanças e fazem parte de um quadro geral da cultura ocidental no século XX. Por isso a abordagem comparativa se faz necessária.

\section{Metodologia}

Abordar as trajetórias de fado, tango e samba de maneira comparada nos permite ampliar o entendimento da relação entre música, sociedade, identidade e patrimônio, e é essa nossa proposta nesse trabalho. Otília Lage aponta que o método comparativo oferece "a possibilidade de duas ou mais realidades histórico-sociais diferentes, contíguas e/ou separadas no espaço e/ou no tempo, serem comparadas sistematicamente, com vista a estabelecer semelhanças, diferenças, generalizações e individualizações" (LAGE, 2018, p. 64).

Conforme aponta José d'Assumpção Barros, a história comparada começa a tomar corpo na década de 1930, quando os excessos dos diferentes nacionalismos europeus passam a representar um mal-estar entre intelectuais, de Marc Bloch a Toynbee, por exemplo. Em suas palavras “"comparar' era, de algum modo, abrir-se para o diálogo, romper o isolamento, contrapor ao mero orgulho nacional um elemento de "humanidade" (BARROS, 2007, p. 9).

Barros também esclarece que a história comparada se refere tanto a um "modo específico de observar a história" como também ao estabelecimento de um duplo ou múltiplo campo de observação (BARROS, 2007, p. 9). 
Assim estão dadas as premissas deste trabalho, partimos do estabelecimento de conexões entre esses três gêneros que nasceram em periferias de capitais portuárias no fim do século XIX e passam as primeiras décadas ligados a setores marginais da sociedade. $\mathrm{O}$ uso da expressão 'capital portuária' aqui não é mero detalhe, as capitais em questão eram núcleos culturais, demográficos, políticos e tecnológicos, bem como o fato de estarem juntas de grandes portos thes proporcionavam maior conexão internacional.

O rádio também imprimiu suas marcas nesses gêneros musicais: as músicas ficaram mais curtas (padrão comercial) e as letras foram disciplinadas (tanto em relação ao pudor moral, quanto na crítica política). Em contrapartida, o rádio ofereceu a possibilidade do estrelato aos outrora marginais (CUNHA, 2004), fazendo-os chegar a parcelas mais abastadas da população e aos rincões mais distantes. Esse arcabouço teórico não pretende eliminar as singularidades e especificidades desses gêneros, mas entendê-los num contexto mais amplo.

Se por um lado o método comparativo busca uma visão conjunta de fenômenos que se repetem com certa frequência, por outro, pretende mostrar as especificidades de fenômenos semelhantes. Desse modo, contemplamos a trajetória comum do fado, tango e samba em meio ao crescimento do sistema de radiodifusão e a ação de governos autoritários - fenômenos globais da época -, bem como os modos peculiares pelos quais artistas tiraram proveito do patrocínio estatal, adaptaram seus repertórios e mutilaram sua liberdade artística. Seguindo a mesma lógica, podemos vislumbrar os processos mais recentes de transformação do fado, tango e samba em símbolos nacionais num esforço de reafirmar originalidade, autenticidade e unicidade.

\section{Resultados}

Dividimos essa apresentação dos resultados em cinco tópicos que abrangem desde os primórdios desses gêneros musicais - marcados pela marginalidade - até a atualidade - como ativos turísticos e símbolos identitários.

\section{Os primórdios}

Se hoje nos parece quase impossível uma pessoa comum com cultura geral mediana confundir fado, tango e samba, antes da consolidação do rádio e de uma melhor definição dos estilos isso era mais comum. Em 1859, um botânico alemão em excursão pelo interior do Brasil, mais especificamente pelo Ceará, escreveria sobre um "fado, que eles chamam de samba, onde se dançam várias danças"” (TINHORÃO, 1988, p. 72-73). Mais tarde, na década de 1920, o grupo Os oito batutas, dirigido por Pixinguinha e contando entre seus integrantes o compositor Donga (autor de Pelo Telefone, o primeiro samba registrado fonograficamente), em viagem pela Argentina anunciava fados e maxixes como repertório tipicamente brasileiro (BASTOS, 2013, p. 22). Ainda que esse segundo caso não demonstre confusão, assinala a confluência desses três estilos notadamente marginais e carregados de influência africana.

Dos três gêneros em questão, o fado, enquanto rótulo, parece ter sido o pioneiro. Estudiosos da cultura portuguesa e do fado apontam que ele nasceu em meados do século XIX em bairros periféricos de Lisboa, ligado a parcelas marginais da sociedade tal qual rufiões e prostitutas (GASPAROTTO, 2019; NERY, 2004). Maria Severa, meretriz, cantadeira e guitarrista é considerada a fundadora mítica do gênero.

Se a região de origem do samba é assunto ainda polêmico - Rio ou Salvador -, não resta dúvida quanto ao samba ter nascido de grupos marginais da sociedade, escravizados e seus descendentes. É também na segunda metade do século XIX que o termo samba vai tomando feições mais conhecidas e reconhecíveis, vinculado inicialmente à roda - fator de maior identificação nos primórdios do samba, em que se executava ritmos diferentes como o maxixe e o corta-jaca, entre outros. No Rio de Janeiro, as rodas de samba começaram na região da Pequena África e então foram ganhando adeptos, mas até a década de 1920 o gênero ainda era visto como coisa do populacho.

O tango também tem origem similar, comumente se diz que ele surgiu na década de 1880, nas duas margens do Rio da Prata, Buenos Aires e Montevideo, porém no lado pobre das duas cidades. Assim como o fado e o samba, o que entendemos por tango hoje era bem diferente do praticado no fim do XIX. A dança entre casais, eternizada pelo cinema, só passou a fazer parte do gênero quando o tango adentrou os ambientes dos bordéis de Buenos Aires - já mais próximo da virada de século. Essa característica marcaria o gênero nas primeiras décadas do século XX, o gênero seria proibido até 1925, por sua obscenidade e erotismo vulgar em combinação com a marginalidade de deus adeptos:

O desaguadouro desta bomba humana, feita de gente humilhada e desprezada, foi o tango. Gringos, criollos e negros fazem a síntese de suas desesperanças e aflições. Os italianos, com sua nostalgia; a melancolia dos galegos, o recato dos vascos, "bárbaros por fora e infantis por dentro'; a sensualidade 
negra do candomblé, a raiva dos criollos despojados, o amor bêbado dos marinheiros, a malevolência dos malandros. São os desamparados, os deserdados, os excluídos, os marginalizados que esta música vem amparar. Pela primeira vez o tango assume, 'em seu sorriso desdentado, o ar triste do mundo. (FERNANDES apud SANTOS, 2011, p. 3)

\section{Rejeição}

Na década de 1860 o fado passa a ser ouvido em ambientes mais nobres, como quintas e teatros, mas ainda carregava a pecha de indignidade (GASPAROTTO, 2019, p. 27). Eça de Queiroz, um dos grandes literatos daquele tempo, expôs:

Atenas produziu a escultura, Roma fez o direito, Paris inventou a revolução, a Alemanha achou o misticismo. Lisboa que criou? O Fado... Fatum era um Deus no Olimpo; nestes bairros é uma comédia. Tem uma orquestra de guitarras e uma iluminação $\mathrm{P}$ cigarros. [...] A cena final é no hospital e na enxovia. O plano de fundo é uma mortalha. (QUEIROZ apud GASPAROTTO, 2014, p. 85)

Com o tango acontece algo parecido. Depreciado pela influência africana numa época em que vigorava o racismo pretensamente científico e identificado com a gente dos conventillos (espécie de cortiço bonaerense onde se apinhavam dezenas de imigrantes em poucos metros quadrados) e dos bordéis, custou a ser aceito pela elite cultural do país, conquanto já fosse apreciado por alguns grupos abastados (ROMERO, 2012). Mais tarde, às vésperas da Primeira Guerra Mundial, o tango alcançaria Paris - espécie de capital cultural mundial de então -, e mesmo assim não era visto com bons olhos pela elite platina. $\mathrm{O}$ embaixador argentino na cidade luz, Enrique Larreta, em entrevista à jornais franceses diz:

É uma dança reservada à lupanares [...] de onde saiu para conquistar a Europa [...] é mais uma espécie de aperitivo sexual que dança. [...] Não; em minha casa não. Há em Paris ao menos um salão onde não se dança o tango argentino e este salão é o da legação argentina. (LARRETA apud ROMERO, 2012, p. 418)

No Brasil, um dos bastiões da ilustração e cultura acadêmica, o senador Rui Barbosa, faria discurso similar quanto ao corta-jaca durante o governo de Marechal Hermes, um gênero muito popular na época e associado ao que mais tarde seria conhecido como samba.
Uma das folhas de ontem estampou em fac-símile o programa da recepção presidencial em que diante do corpo diplomático, da mais fina sociedade do Rio de Janeiro, aqueles que deviam dar ao país o exemplo das maneiras mais distintas e dos costumes mais reservados elevaram o corta-jaca à altura de uma instituição social. Mas o corta-jaca de que eu ouvia falar há muito tempo, que vem a ser ele, Sr. Presidente? A mais baixa, a mais chula, a mais grosseira de todas as danças selvagens, a irmã gêmea do batuque, do cateretê e do samba. Mas nas recepções presidenciais o corta-jaca é executado com todas as honras de música de Wagner, e não se quer que a consciência deste País se revolte, que as nossas faces se enrubesçam e que a mocidade se ria! (BARBOSA apud GASPAROTTO, 2019, p. 22)

Em um contexto de redefinição da identidade cultural lusitana marcado pelo signo da decadência, a geração de Eça de Queiroz estava empenhada em entender o atraso português - diante das potências europeias da época - ao mesmo tempo em que folcloristas românticos se ocupavam de inventariar o cancioneiro rural "tipicamente português". Não havia espaço para um gênero recente, sem tradição, popular e marginal entre os bastiões respeitáveis da cultura (GASPAROTO, 2014, p. 85). Tal espaço só surgiria com um novo regime, que procurava redefinir a cultura e a identidade do país. A República chegou em 1910, embora o impulso decisivo nessa questão só tenha acontecido na década seguinte.

O caso argentino soa similar, embora tenha ocorrido mais tarde. Após um excelente período de crescimento econômico - em 1880 a economia argentina era metade da brasileira, em 1916 equivalia ao dobro (ROMERO, 2012, p. 384) - e o recebimento de grandes contingentes migratórios, os planos da elite para a cultura centravam-se na massificação escolar e nacionalização dos imigrantes, priorizando o criollismo em detrimento do cosmopolitismo, estando o tango associado a este último na virada do século. "Circulando por prostíbulos, bares, cafés e festas populares, os primeiros tangos refletem um mundo social avesso ao que haviam ideado as elites" (ROMERO, 2012, p. 372). Essas tendências fizeram surgir um novo rótulo, o tango criollo com apelo a essa identidade (ROMERO, 2012, p. 372).

Ainda na virada do século, outra variedade seria adicionada ao estilo, o tango-canção. Mais adiante, na década de 1920, o panorama se torna ainda mais variado. A obscenidade típica dos primórdios dá lugar à introspecção e o tango adquire caráter de "crônica popular e melancólica da vida cotidiana" (SANTOS, 2011, p. 4). O compositor Enrique Discépolo introduz a problemática social em suas canções, que aliam pessimismo e militância anarquista. 
Como nos casos do fado e do samba, os anos 1920 seriam decisivos para consagração do rótulo, aprimoramento do estilo e difusão em território nacional.

\section{A era do rádio}

O fado passa por uma série de transformações na década de 1920: surge uma nova geração de fadistas, como Berta Cardoso, Hermínia Silva, Ercília Costa e Alberto Costa - é criada a profissão de fadista pelo Decreto $n^{\circ}$. 13.564/1927; surgem casas de espetáculo dedicadas ao fado, entre as quais o Solar da Alegria (1928) é o maior exemplo.

Já num contexto ditatorial, o decreto citado instituía normas para a apreciação do fado: recomendava o silêncio durante as apresentações artísticas com o objetivo de diminuir a arruaça típica de então e obrigava o registro e licenciamento de canções, censurando as letras, porém estabelecendo um sistema de recompensa financeira para os compositores. Nery (2004) ressalta que essas medidas acabariam por engessar a prática fadista interferindo na característica principal do gênero naquela altura: a improvisação.

Simultaneamente a esse processo de institucionalização, ocorria o desenvolvimento das tecnologias de gravação em disco e radiodifusão que também viriam a deixar suas marcas na formatação do gênero. As novas tecnologias também possibilitaram a difusão do fado para fora da capital e para fora de Portugal, tornando-o um produto tipicamente português aos olhos dos lusitanos e em outros países. Tal processo ocorre no regime salazarista, com seu apoio, ainda que o fenômeno não deva ser reduzido a essa relação.

No caso do fado, pontua Falcão:

A ampliação da divulgação do fado através da rádio e da indústria fonográfica e do cinema encontram em Amália Rodrigues a sua expressão máxima. A importância de Amália está relacionada com o seu papel de celebridade, como o maior mito do fado e, segundo alguns, como uma personificação do fado (HALPERN, 2004, p. 47). A primeira gravação da fadista ocorreu durante uma digressão, em 1944, no Rio de Janeiro, Brasil. O seu sucesso na capital brasileira, seguida de uma digressão em Paris, fizeram da cantora um ícone com interesses para representar a imagem de Portugal no exterior. Amália Rodrigues foi uma estrela do fado divinizada por seus fãs, denominados por Gray de “amalianos". (FALCÃO, 2017, p. 48)

No caso brasileiro, ainda que internamente não seja um ícone do samba à primeira vista ou o nome mais lembrado quando se fala no gênero, Carmem Miranda desempenhou papel similar ao de Amália, tanto na indústria fonográfica e cinematográfica, quanto aos olhos do público internacional. Esse contexto internacional de circulação de mídias e modelos artísticos não é de menor importância - própria Carmem Miranda nasceu em Portugal, ainda que tenha chegado ao Brasil com apenas dez meses de vida.

A troca de regime no Brasil se dá em 1930, e durante a Era Vargas (1930-1945) o samba vai "da marginalidade ao estrelado" (CUNHA, 2004). Mais uma vez, essa ascensão não deve ser reduzida exclusivamente à relação com Vargas, embora tenha suas ligações. Se tomarmos duas canções ícones, como a já mencionada Pelo Telefone, de 1916, e a mundialmente famosa Aquarela do Brasil, composta por Ary Barroso em 1939, veremos um processo de disciplinarização patrocinado por Vargas, no qual temas como a malandragem e boemia são substituídos pela exaltação patriótica e elogio do trabalho.

O tango continuou a se popularizar nos anos 1930, agora sendo tocado por grandes orquestras ao vivo e ganharia ainda mais força nos anos 1940, graças ao rádio e a Juan Perón. A essa altura, o tanguero Discépolo se torna um dos maiores responsáveis pela difusão do estilo, agora alinhado ao peronismo.

Ao definir o tango como a expressão de "todas as latitudes do sentir argentino", Giacobre, um dos ideólogos peronistas, demonstra a preocupação do regime em consagrar o tango como a genuína música argentina, estratégia que fez parte da política estatal de valorização da cultura popular numa tentativa de se aproximar dos grupos marginalizados da sociedade, especialmente os trabalhadores urbanos, que se constituíram na principal base de sustentação do governo de Juan Perón entre os anos de 1946-1955. (SANTOS, 2011, p. 2)

Cabe esclarecer que o tango já desfrutava do gosto popular, principalmente em Buenos Aires, a novidade com Perón é a nacionalização do gênero, no âmbito de sua política para as massas e da possibilidade tecnológica criada pelo sistema de radiodifusão.

Descritas essas trajetórias e constatadas algumas semelhanças fundamentais, passaremos a seguir à discussão da transformação dessas manifestações da cultura popular em patrimônios protegidos e ativos turísticos.

\section{A questão patrimonial nos anos 1990}

Ao fim do século XX, a noção de patrimônio cultural se apresenta bem diferente de um século atrás. Durante alguns séculos - pelo menos desde a Revolução 
Francesa - imperou um modelo preservacionista de gestão patrimonial, marcado pela forte ação do Estado e caráter elitista na eleição de produtos para serem preservados. Sob esse paradigma, objetos eram escolhidos pela excepcionalidade estética ou vinculação a acontecimentos memoráveis da história nacional. Tal modelo era marcado por uma perspectiva imobilista que buscava manter os objetos "congelados" - preservados sem nenhuma mudança. A preocupação fundamental nesse sistema era a preservação e pouco importava se as peças estariam aos olhos do grande público. Já com o avançar do século XX surgiriam outros modelos de gestão patrimonial, como o da conservação integrada, que visava o entorno, a ambiência e o significado para além dos objetos colecionáveis e preserváveis (STARLING, 2011, p. 5). Acompanhando a metamorfose do conceito de cultura - que passa a abranger as manifestações populares e os produtos de massa-essa concepção de patrimônio demandava novas ações: "o simples tombamento de edificações ou conjuntos urbanos dá lugar às ações que visam conservar o equilíbrio da paisagem urbana e natural" (STARLING, 2011, p. 5).

O modelo de conservação integrada teve origem na Itália e Espanha dos anos 1970, segundo Mônica Starling:

Nos dois países, a conservação integrada serviu como argumento teórico e prático para as administrações municipais de esquerda, e suas realizações como bandeira para a construção de uma imagem política de eficiência administrativa, justiça social e participação popular nas decisões do planejamento urbano e regional. (STARLING, 2011, p. 6)

A preocupação com as comunidades locais e ações das municipalidades em face as ações dos Estados Nacionais típicas do modelo anterior era uma das linhas mestras desse modelo. Contudo, se inicialmente a conservação integrada visava ao uso social do patrimônio, com o passar das décadas essa referência se perdeu e os resultados econômicos advindos das revitalizações, sobretudo relacionadas a empreendimentos imobiliários, foram priorizados. O esgarçamento dessa noção viria a resultar num terceiro modelo de gestão patrimonial, o de reabilitação:

pautando-se, da mesma forma que o modelo da conservação, por uma por uma concepção ampliada de patrimônio cultural e tendo também como objeto o "patrimônio ambiental urbano", o modelo de reabilitação tem como principal diferencial em relação ao modelo anterior, a importância atribuída ao desenvolvimento e sustentabilidade econômica das áreas conservadas. Esse diferencial se desdobra em novos elementos e características que passam a compor as intervenções com foco no desenvolvimento urbano. (STARLING, 2011, p. 8)

Essa transformação não se dá ao sabor do acaso, mas justamente em um contexto de crise da social-democracia e ascensão do neoliberalismo em nível global, além do desmanche soviético. Para Starling, outra diferença importante entre esses dois modelos de gestão patrimonial é a constituição das equipes por trás desses projetos: enquanto no modelo de conservação integrada predominavam arquitetos e historiadores, na reabilitação atores empresariais ganham protagonismo. Segundo a autora, acontece um enobrecimento de espaços antes degradados, porém com o efeito colateral da segmentação e exclusão social de grupos que não se encaixam no novo e alto padrão de consumo instituído nos espaços reabilitados.

Também partindo de uma concepção ampliada de patrimônio, o mais recente modelo de gestão patrimonial, dentre os definidos por Mônica Starling (2011), busca a inclusão de mais atores nos processos decisórios:

o diferencial mais importante nesse modelo - que denominaremos governança deliberativa - é a inclusão de novos atores à discussão e ao debate das políticas públicas que pode estimular uma maior capacidade de negociação entre interesses públicos e privados. [...]

Destaca-se ainda a integração de profissionais de diversas áreas: antropólogos, cientistas sociais, historiadores, arquitetos, planejadores urbanos, profissionais do turismo, produtores culturais e profissionais do marketing, de forma a construir um olhar mais abrangente e adequado a concepção alargada de patrimônio cultural. (STARLING, 2011, p. 14)

A transformação do conceito de cultura e a evolução da noção de patrimônio coincidiram temporalmente com o desenvolvimento da indústria turística de modo a se retroalimentarem. Com o adiantamento do processo de globalização, principalmente pela integração de mercados pós-Guerra Fria, observa-se um processo - ainda em curso - de valorização das culturas locais e de seus patrimônios típicos. Diante de uma cultura internacionalizada que avança barreiras com a força do capital, a valorização de produtos peculiares de cada cultura passou a ser visto como fator de marketing, além dos aspectos identitários já conhecidos. No caso brasileiro, se o país tem belas praias, mas não possui uma rede hoteleira de qualidade suficiente para disputar o topo dos destinos receptores, o samba poderia ser o diferencial e dar gosto único à 
paisagem brasileira. Nessa lógica são estimulados projetos que buscam o "resgate e promoção da cultura".

No entanto, entre as diversas manifestações culturais originais e legítimas que os diversos povos produzem, aquelas que tinham maior potencial turístico receberam maior atenção e investimento por parte dos governos. Além do esmaecimento de práticas e patrimônios "não turísticos", outro efeito colateral surgido nesse processo é o encarecimento desses fenômenos culturais como o samba, tango e fado para suas comunidades originárias, motivado pela diferença cambial (CUNHA, 2009; MOREL, 2013; RODRIGUES, 2016). Eduardo Falcão conclui que:

a utilização do selo "fado património da humanidade" da Unesco está marcada por interesses privados que empregam o património como ferramenta para finalidades distintas das propostas pelo Convenção do PCI. A atribuição de valor patrimonial aparece pautada por um imperativo de diversos usos económicos consoante os diferentes atores sociais implicados. Assim, sustento que a utilização e prática do fado na cidade do Porto foi apropriada, em certa medida, pela indústria do turismo, onde o surgimento de novos espaços para a prática do fado se destina principalmente aos turistas. Neste sentido, o fado foi resinificado como valor simbólico da marca Portugal e transformou-se em mais um recurso disponível para gestão dos setores privados. (FALCÃO, 2017, p. 125)

Contudo, seria errôneo considerar apenas o aspecto econômico, pois:

Atualmente o fado desempenha um duplo papel na sociedade portuguesa contemporânea: de valor identitário e de potencial económico. Assiste-se, assim, à ampliação e à consolidação do fado como um bem cultural capaz de ser consumido e de prover uma identidade portuguesa. (FALCÃO, 2017, p. 126)

Devemos estar atentos para os processos de patrimonialização do fado, tango e samba dentro desse panorama complexo: ampliação da noção de cultura, surgimento de novos modelos de gestão patrimonial, redemocratização de Portugal, Argentina e Brasil e, finalmente, o desenvolvimento da indústria do turismo ao longo do século XX e XXI. Contudo, retomando a perspectiva comparativa, há de se ressaltar que fado e tango receberam a chancela de patrimônio cultural imaterial da Unesco, ao passo que ela foi inicialmente negada ao samba (carioca) por não haver risco de extinção. Anos depois, o samba do recôncavo baiano foi agraciado com a honraria. Note-se que a própria política de preservação de patrimônio imaterial da Unesco foi alterada nessas décadas. Quando da tentativa de patrimonialização do samba, o instrumento legal acordado pela Convenção do Patrimônio Cultural Imaterial da Humanidade era a declaração de "Obras-Primas do Patrimônio Oral e Imaterial da Humanidade". Já nos processos que envolveram Tango e Fado, estava em jogo a chancela de Patrimônio Cultural Imaterial (PCI) e o "risco de extinção" não era mais um critério (FALCÃO, 2017 , p. 24). Apesar dessa diferença, há de se notar que, quanto ao caminho da patrimonialização dentro de cada país, os três processos são razoavelmente parecidos.

\section{Patrimônio e Turismo: fado, tango e samba como ativos turísticos}

Existe uma tensão entre a preservação da autenticidade do patrimônio e o crescimento da indústria turística em importantes cidades do mundo, de Veneza a Paraty. Ela também se faz presente em Lisboa no tocante ao fado, de acordo com Rodrigues:

Cada vez mais encenado para um público estrangeiro, o fado vai procurando manter a sua autenticidade e dando voz ao galardão recebido, através da preservação e valorização da identidade cultural presente no bairro mais antigo da capital portuguesa. Por sua vez, Alfama tenta conservar o seu cunho tradicional e bairrista, como sempre foi conhecida, acompanhando uma nova dinâmica social devido à presença de forasteiros, ao mesmo tempo que se tenta evitar a sua descaracterização. (RODRIGUES, 2016, p. 5)

O turismo é um dos seus pilares econômicos de Portugal e o fado contribui para atração de turistas. Reconhecido como Patrimônio Imaterial da Humanidade pela Unesco em 2011, desde então passou a ser uma das estrelas publicitárias das campanhas de divulgação do país como destino turístico (SOUZA, 2014, p. 192). Bairros tradicionais de Lisboa como Mouraria, Madragoa e Bairro Alto, junto de Alfama - "o berço do fado" - assistem a proliferação de restaurantes e casas de espetáculo visando o apelo turístico conferido ao fado. O modo como essas casas combinam fado e gastronomia é um fenômeno importante de se observar, pois apesar de aumentarem a lucratividade de tais estabelecimentos e da indústria turística em geral, trazem efeitos colaterais, como aponta Souza:

O fado faz parte do conjunto da vida cultural e social portuguesa, sendo que os preços cobrados pelos estabelecimentos em muitas ocasiões são altos, afugentando moradores e 
maximizando a presença dos turistas que vão aos bairros tradicionais à procura do gênero. (SOUZA, 2014, p. 193)

Segundo Jorge Mangorrinha, "no turismo o que conta é cada vez mais a diferença dos destinos e produtos para a captação de uma procura qualificada que valorize a nossa oferta turística" (MANGORRINHA apud SOUZA, 2014, p. 198) e, nessa busca por autenticidade, tanto por parte dos turistas que procuram novas experiências, quanto dos destinos receptores que visam agregar valor ao produto, há de se tentar equilibrar esses interesses diferentes - e por vezes conflitantes - para que a indústria do turismo não sufoque a cultura. Quanto ao fado, alinhado às críticas de Morel no caso do tango, Falcão aponta que

o novo contexto em que se encontra a prática fadista e o respetivo sucesso da legitimação enquanto política patrimonial da Unesco acarretou a transformação do fado num objeto comercial genérico. Isto traduz-se numa certa homogeneização da oferta que, segundo Ronström (2014, p. 46), é um dos pré-requisitos necessários para o desacoplamento da prática musical de seu antigo contexto, com o objetivo de alcançar uma maior distribuição global. Nesta homogeneização três aspetos são destacados por Ronström acerca da padronização da música: a "historização", a "estetização" e a "autenticidade". Assim, aplicados ao estudo de caso do fado, é verificável a presença destes aspetos. Em primeiro lugar a oferta de um fado patrimonializado acarreta uma forte "historização", através da anexação de um carregado discurso histórico. (FALCÃO, 2017, p. 116)

Na Argentina, o tango ascende à categoria de grande ativo turístico nos anos 2000 e, logo nos primeiros anos, já era possível observar alguns dos efeitos colaterais que apontamos. Casas de espetáculo destinadas a turistas recebiam clientes que gastavam, em média, 160 pesos, enquanto nas casas voltadas à população local o gasto médio era apenas 16 pesos. Na lista dos dez lugares da capital mais visitados por turistas, cinco são ligados ao tango, e as estimativas da economia tanguera para 2006 eram de 400 milhões de pesos (SENKIW, 2017).

Segundo Hernán Morel, desde os anos 1990 há um esforço em transformar Buenos Aires na "Meca do Tango", tanto pelo caráter identitário, quanto turístico-econômico. Houve até quem chamasse o tango de "a soja portenha" (MOREL, 2013, p. 69). Morel ressalta que o aspecto cultural, identitário, tem ficado em segundo plano diante do turístico e isso se traduz em ações como a organização de grandes festivais voltados ao público estrangeiro ao invés de apoiar inciativas locais. Até mesmo a agenda desses eventos segue o calendário europeu e contribui para uma elitização dos espetáculos com elevação dos preços, excluindo a população local. O preço é tão alto que se torna impraticável como hábito rotineiro da maior parte da população, promovendo um descolamento do tango perante sua comunidade produtora.

Ao lado das medidas que visam a lucratividade do tango como negócio, adotam-se ações preservacionistas como a criação da Academia del Tango, por Carlos Menem em 1990, nascida com o objetivo de recompilar, ordenar, estudar e salvaguardar de toda possibilidade de perda ou destruição o tango e suas produções. A academia também indicava que o gênero deveria ser objeto de docência e tinha como missão difundi-lo nacional e internacionalmente e ainda incentivar novas criações (MOREL, 2013, p. 61). Esse movimento de salvaguarda atinge maior grau com a chancela de Patrimônio Imaterial dada pela Unesco em 2009, o que lhe confere maior autenticidade. Observe-se que os processos museológicos e patrimoniais postos em prática pela Academia del Tango embasam o processo institucional de salvaguarda que culmina no reconhecimento por parte da Unesco.

Quanto ao samba, também seria nos anos 2000 que sua patrimonialização e transformação em ativo turístico ganhariam contornos mais evidentes. Desde as iniciativas do Iphan ao inscrever no Livro de Registro de Expressões de Bens Imateriais três tipos de samba - o partido alto, o de terreiro e o samba-enredo - até outros projetos como a criação do Museu a Céu Aberto do Morro da Providência, por exemplo - museu idealizado pela arquiteta Lu Petersen para revitalizar a zona portuária junto da criação da Cidade do Samba e da Vila olímpica da Gamboa (CUNHA, 2009, p. 52). Ainda poderíamos citar a criação do Museu do Samba e o Centro Gultural Cartola. Todas essas medidas que criam um arcabouço institucional e aumentam o reconhecimento à cultura popular pelo poder público, são ações que ajudam a formatar o samba como produto turístico.

Como nos outros casos, são observados efeitos colaterais, como o encarecimento dos espetáculos para o público local. Vale notar que no Rio de Janeiro, e principalmente em Buenos Aires, isso se agrava pela disparidade cambial.

\section{ConsideraÇÕES FINAIS}

Aguilar Criado aponta que a dinâmica atual do patrimônio cultural tende a fazer emergir a força dos valores locais como marca de distinção diante da homogeneização 
de práticas culturais globais (MOREL, 2013, p. 59-60). Esse é um ponto importante que justifica nossa opção pelo método comparativo na medida em que é possível observar certas premissas nos três casos, e ainda haveria outros já que se trata de condições senão globais, ao menos internacionais. Nos referimos especificamente ao contexto de circulação transnacional de modelos culturais na Belle Époque (COOPER-RICHET, 2012.), período que nutriu uma utopia liberal baseada no intercambio global de produtos "nacionais" segundo a lógica do diamante liberal cada aresta é um país que contribui para o Concerto das Nações com seu melhor lado (SEVCENKO, 1983), bem como a era do rádio, entre os anos 1930 e 1950 e, por fim, o contexto neoliberal dos anos 1990, transcorrido nos três países, após o fim de experiências ditatoriais.

Nos casos observados aqui podemos notar um movimento que envolve internacionalização de práticas culturais simultâneo a um resgate da tradição e valorização das culturas e identidades locais nos vetores temporais que abordamos. Como aponta Clifford Geertz, o capital é móvel e:

Não importa o que desejemos ou encaremos como escla-
recimento, a diversidade das culturas persiste e prolifera,
mesmo em meio e até em resposta às poderosas forças de
vinculação da indústria, das finanças, das viagens e do comér-
cio modernos. Quanto mais as coisas se juntam, mais ficam
separadas: o mundo uniforme não está muito mais próximo
do que a sociedade sem classes. (GEERTZ, 2001, p. 217)

Nas décadas iniciais do século XX, a tecnologia aliada ao capital e poder político transforma práticas culturais locais em símbolos nacionais. Ao fim do século XX e início do XXI, observamos um movimento de patrimonialização, marcado pelo resgate da tradição enquanto elemento identitário e desenvolvimento da indústria turística e consequente exploração econômica.

O impacto do capital e do poder político nesses processos é inegável e decisivo, contudo, seria errôneo deslegitimar o caráter popular e original de cada uma dessas manifestações. Buscamos mostrar a complexidade desses fenômenos culturais global e localmente. Do mesmo jeito que a objetificação turística produz efeitos perversos nas comunidades de origem, o bom funcionamento da indústria turística pode assegurar emprego e melhores condições de vida contingentes preteridos há séculos.

Não existe uma estratégia que articule automaticamente os interesses patrimoniais e culturais aos turísticos e econômicos, desse impasse é que emerge a necessidade do modelo de gestão patrimonial da governança deliberativa, instrumento que visa a salvaguarda do patrimônio, mas que evita tanto a museificação dos espaços e a elitização dos espetáculos.

Movimentos de resgate, valorização, panteonização, patrimonialização e museificação de diversas manifestações culturais populares no fim do século XX tomaram corpo após a redemocratização de Portugal, Argentina e Brasil e isso não é mera coincidência. Mas, ao lado desses gestos políticos e sociais, a influência neoliberal também se fez presente, formatando e filtrando manifestações culturais com apelo turístico, por vezes imputando o esquecimento social e abandono por parte do poder público de expressões culturais não atrativas para a indústria turística. A criação desses produtos turístico-culturais coincidiu com a promoção do multiculturalismo por parte da ONU e Unesco. Por sua vez, o multiculturalismo cresceu e ganhou adeptos com a intensificação do turismo internacional nas últimas décadas.

Diante deste cenário, as atuais políticas patrimoniais procuram operar de forma a fornecer certezas de um porto seguro em que se torne possível atracar uma identidade. Diante da pluralidade cultural global, a patrimonialização permite a reivindicação dos particularismos, em que cada localidade pretende afirmar-se ao elaborar um discurso de ligação às raízes e de valorização de uma herança cultural única. A patrimonialização e as reafirmações particularistas funcionam como meios de personalização, de ser autêntico e de se sentir orgulho nelas. (FALCÃO, 2017, p. 32)

O novo contexto de circulação de bens e pessoas, marcado pela internacionalização da mão de obra e pelo intercâmbio de estudantes aliados ao potencial de difusão midiática da internet, estimulou a busca por produtos culturais "autênticos" e "únicos". É nesse movimento de busca pelo "original" - às vezes exótico - que emergiram políticas públicas de salvaguarda de patrimônios culturais, principalmente os imateriais e os empreendedores do século XXI entenderam que as marcas de sucesso pautam suas operações em experiências de consumo. Nesse elo repousa a possibilidade de articular turismo e patrimônio.

\section{REFERÊNCIAS}

BASTOS, R. O fado como integrante do sistema de transformações lundu-modinha-fado: notas para um modelo histórico-antropológico das relações musicais 
brasil/portugal/áfrica. In: VALENTE, H. (org.). Trago o fado nos sentidos: cantares de um imaginário atlântico. São Paulo: Letra e Voz, 2013. p. 18-31.

BARROS, J. D. História comparada - da contribuição de Marc Bloch à constituição de um moderno campo historiográfico. Histyria Social, Campinas, n. 13, p. 7-21, 2007.

\section{COOPER-RICHET, D. Transferkncias Culturais,} circulaзro de ideias e proticas: o caso da França e do Brasil no século XIX. Tradução de Valéria Guimarães. Assis: VI Encontro do CEDAP, 2012.

CUNHA, F. Da marginalidade ao estrelato: o samba na construção da nacionalidade. São Paulo: Annablume, 2004.

CUNHA, F. As matrizes do samba carioca e carnaval: algumas reflexões sobre patrimônio imaterial. Patrimфnio e Memyria, Assis, v. 5, n. 2, p. 34-57, 2009.

FALCÃO, E. Toda a gente virou fadista: ressonâncias do processo de patrimonialização do fado na cidade do Porto. 2017. Dissertação (Mestrado em História) Universidade do Porto, Porto, 2017.

GASPAROTTO, L. Alma e destino do povo português: a fado como identidade nacional lusa no limiar do Estado Novo (1927-1933). Oficina do Historiador, Porto Alegre, v. 7, n. 2, p. 80-96, 2014.

GASPAROTTO, L. Se nго й canзго nacional, para 1б caminha: a presentificação da nação na construção do samba e do fado como símbolos identitários no Brasil e em Portugal (1890-1942). 2019. Tese (Doutorado em História) - PUG-RS, Porto Alegre, 2019.

\section{GEERTZ, C. Nova luz sobre a antropologia.} Rio de Janeiro: Zahar, 2001.

LAGE, O. História comparada e método comparativo historiográfico: problemas e propostas. Atas do Workshop Alto Douro e Pico. Paisagens culturais vinhateiras Património mundial em perspectiva multifocal: experimentação comparada, Porto, 2018.

MOREL, H. Buenos aires, la Meca del tango: procesos de activacion, megaeventos culturales, turismo y dilemas en el patrimonio local. Publicar, Buenos Aires, v. 11, n. 15 , p. 55-74, 2013.

NERY, R. V. Para uma histyria do fado. Lisboa: Público: Corda Seca, 2004.

RODRIGUES, I. O Fado e a valorizasro turhstica dos bairros lisboetas: estudo de caso no bairro de Alfama. 2016. Dissertação (Mestrado em Turismo e Educação) - Universidade de Lisboa, 2016.

ROMERO, A. Buenos Aires, história e tango: crise, identidade e intertexto nas narrativas "tangueras". 2012. Tese (Doutorado em História) - Universidade Federal Fluminense, 2012.

SANTOS, R. "Mi Buenos Aires querido": o tango como expressão da nacionalidade argentina nas políticas culturais do regime peronista (1946-1955). In: SEMINÁRIO INTERNAGIONAL DE POLÍTICAS GULTURAIS, 2., 2011, Rio de Janeiro. Anais [...]. Rio de Janeiro: Fundação Casa de Rui Barbosa: Itaú Cultural, 2011.

SENKIW, M. Tango, dimensión económica y turismo. Blog Fractura Exposta, [S. l.], 17 mar. 2017. Disponível em:http://www.fracturaexpuesta.com.ar/tango-economiay-turismo/. Acesso em: 5 abr. 2021.

SEVCENKO, N. O cosmopolitismo pacifista da Belle Époque: uma utopia liberal. Revista de Histyria, São Paulo, n. 114, p. 85-94, 1983. São Paulo, 1983, p. 85-94.

SOUZA, R. N. de. Um turismo afadistado: uma análise dos usos turísticos e de lazer do fado nos bairros tradicionais de Lisboa. Revista Semina, Passo Fundo, v. 13, n. 1, p. 189-199, 2014.

STARLING, M. Entre a lógica de mercado e a cidadania: os modelos de gestão do patrimônio cultural. In: SEMINÁRIO INTERNACIONAL DE POLÍTICAS CULTURAIS, 2., 2011, Rio de Janeiro. Anais [...]. Rio de Janeiro: Fundação Casa de Rui Barbosa e Itaú Cultural, 2011.

TINHORÃO, J. R. Os sons dos negros no Brasil: cantos, danças, folguedos - origens. São Paulo: Art editora, 1988. 